\title{
Konsep Hibah Bersyarat dan Aplikasinya dalam Perancangan Harta (The Concept of Conditional "Hibah" and its Application in Property Planning)
}

\author{
Nasrul Hisyam Nor Muhamad, ${ }^{a}$ Ahmad Che Yaacob, ${ }^{b}$ Norazila Mat Hussain. ${ }^{c}$ \\ a,b,c Fakulti Tamadun Islam \\ Universiti Teknologi Malaysia \\ *Corresponding author: nasrul@utm.my
}

\begin{abstract}
Abstrak
Hibah bersyarat telah menjadi salah satu produk yang semakin popular dalam perancangan harta di Malaysia. Artikel ini bertujuan menganalisis kedudukan hibah bersyarat mengikut perspektif undang-undang Islam dan juga mengkaji aplikasi serta potensi penggunaan hibah bersyarat dalam perancangan harta. Di samping itu, artikel ini juga membincangkan antara isu-isu yang timbul daripada pemakaian hibah bersyarat. Kajian ini berbentuk kualitatif dan menggunakan pendekatan analisis kandungan. Daripada keseluruhan perbincangan dalam kajian ini, disimpulkan bahawa hibah bersyarat mempunyai kedudukannya yang tersendiri dalam perundangan Islam di Malaysia. Hibah bersyarat dilihat sangat berpotensi menjadi satu instrumen yang sangat berkesan dalam perancangan harta, ini kerana instrumen hibah bersyarat lebih fleksibal dan tidak terhad sebagaimana faraid dan wasiat.
\end{abstract}

Kata kunci: Undang-undang Islam, perwarisan, perancangan harta, hibah bersyarat

\begin{abstract}
The 'gift with conditions' has become one of the increasingly popular products in property planning industry in Malaysia. The article aims to analyze the position of the 'gift with conditions' based on the perspective of Islamic law and also its applications as well as the potential of using that concept in property planning. In addition, this article also discusses the issues arising from its application. This study is qualitative and uses a content analysis approach. From the whole discussion in this study, it is concluded that the 'gift with conditions' has its own position in Islamic law in Malaysia. This concept are seen to have the potential to be an effective instrument in property planning, as the 'gift with conditions' are more flexible and unlimited as in faraid and will.
\end{abstract}

Key words: Islamic law, inheritance, property planning, the 'Gift with Conditions' 


\subsection{PENDAHULUAN}

Perancangan harta dalam Islam sangat penting terutama dalam zaman moden ini ketika masyarakat berhadapan dengan pelbagai cabaran baru dalam konteks kehartaan. Antara cabarannya ialah kecenderungan mementingkan kebendaan sehingga boleh mencetuskan pertikaian serta permusuhan di antara suami isteri, ibu bapa, adik beradik, saudara mara, dan sebagainya. Apabila kebendaan dijadikan kayu ukur utama, krisis keluarga lebih mudah berlaku dan rumah tangga mudah menjadi porak peranda. Krisis keluarga akibat kepentingan kebendaan bertambah parah dengan tiadanya kefahaman masyarakat tentang ilmu pembahagian harta pusaka atau apa yang disebut sebagai ilmu faraid dan ilmu berkenaan perancangan harta (Norazila Mat Hussin, 2012). Berdasarkan kepentingan perancangan harta yang dijelaskan ini, maka pengkaji akan membincangkan mengenai aplikasi dan potensi hibah bersyarat sebagai instrumen perancangan harta.

\subsection{KONSEP HIBAH BERSYARAT}

Dari segi pentakrifan, perkataan hibah digunakan untuk maksud memberi kelebihan dan kebaikan dengan suatu yang boleh membawa manfaat kepada penerima sama ada yang diberi itu berupa harta atau bukan harta. Namun demikian, apabila merujuk kepada pengertian dari sudut istilah, maka hibah akan dirujuk sebagai harta sahaja ('Ali Haydar, t.t; Ibn 'Abidin, 1966; al-Jaziri, t.t.). Dari segi fiqh, hibah boleh dirumuskan sebagai satu akad pemberian milik secara sukarela semasa hidup pemilik harta kepada seseorang tanpa balasan (al-Sharbini, t.t.; al-Nawawi, t.t.).

Berdasarkan konsep hibah dalam fiqh tersebut, maka pemberian hibah mestilah dibuat secara mutlak, tanpa syarat, mahupun balasan. Hibah mutlak yang turut dikenali sebagai al-hibah almunjizah apabila telah memenuhi rukun dan syaratnya akan memberi tiga kesan berikut (Nasrul Hisyam, 2011):

i. Mawhub akan berpindah milik kepada penerima hibah berkuatkuasa serta-merta

ii. Hak milik penerima hibah adalah kekal dan tidak dihadkan tempohnya

iii. Hilangnya hak milik penghibah terhadap 'ayn dan manfaat mawhub

Hibah dikategorikan dalam akad yang melibatkan transaksi milikan daripada seseorang kepada seorang yang lain. Secara umumnya, akad-akad yang melibatkan pindah milikan ('uqud al-tamlik) adalah termasuk dalam kategori akad yang tidak sah dengan kemasukan syarat ta'liq, tawqit dan idafah melainkan akad wasiat. Walau bagaimanapun, mengikut pandangan mazhab Maliki, kaedah umum ini dikecualikan kepada akad-akad sukarela (tabarru') termasuk juga hibah ('Ali al-Khafif, 1996).

Sungguhpun demikian sekiranya penerima hibah (mauhub lahu) hendak membalas pemberian tersebut ia adalah perbuatan sunat. Perkara ini sabit dengan sebuah hadis daripada Saidatina Aisyah telah berkata (al-'Asqalani, Ibn Hajar, t.t.: 5/254):

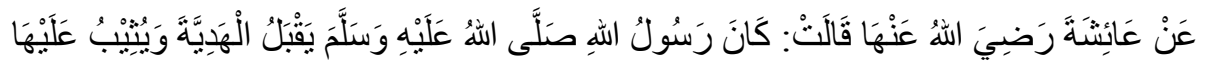

$$
\begin{aligned}
& \text { Maksud: Dari 'A'ishah bahawa Rasulullah S.A.W. biasa menerima } \\
& \text { hadiah dan membalasnya". }
\end{aligned}
$$

(Al-Bukhari)

Terma "tanpa balasan" dalam konsep asal hibah inisecara eksplisit menggambarkan hibah dengan syarat balasan (hibah bi shart 'iwad) tidak termasuk dalam erti kata hibah. Walhal, hibah dengan cara tersebut juga diiktiraf sebagai hibah yang sah, mengikut atau tertakluk kepada pendapat para fukaha pelbagai mazhab (Nasrul Hisyam, 2011). Berdasarkan hakikat ini, Muhammad Qadri Basha (1338H) dalam Murshid al-Hayran mentakrifkan hibah sebagai, "Pemberian milik "ayn harta secara tanpa balasan dan kadang kala disertai balasan.” 
Selain itu, terdapat undang-undang sivil negara Islam yang walaupun tidak menyebut mengenai elemen balasan dalam peruntukan takrif hibah, namun memperuntukkan dalam sub perkara yang sama mengenai keharusan mensyaratkan balasan. Hal ini boleh dilihat daripada peruntukan-peruntukan Perkara 557 (1) dan (2), Undang-undang Sivil Jordan; Perkara 200, Undang-undang Sivil Tunisia, Perkara 614 (1) dan (2), Undang-undang Sivil UAE.

Oleh yang demikian, penulis merumuskan bahawa definisi hibah yang merangkumi hibah bi shart 'iwad ialah "Satu akad pemberian hak milik harta semasa hidup secara sukarela kepada orang lain semasa hidup secara percuma atau dengan balasan yang tidak menafikan hakikat tabarru" pemberian tersebut".

Berdasarkan pandangan umum dalam fiqh, hibah adalah pemberian yang dilakukan secara sukarela dan tanpa meletakkan sebarang syarat untuk menguatkuasakannya. Oleh yang demikian, mengikut konsep asal ini, hibah berbentuk kategori hibah bersyarat atau conditional hibah adalah tidak sah kerana bercanggah dengan kehendak dan sifat akad hibah (Kamila Tyabji, 1949):

i) Sighah berbentuk idafah adalah bertentangan dengan sifat akad hibah yang memberi pemilikan secara serta-merta selepas akad dan qabd.

ii) Sighah tawqit menggambarkan bahawa penghibah mengehadkan tempoh pemilikan mawhub, sedangkan akad hibah merupakan pemberian milik yang kekal kepada penerima hibah.

iii) Sighah ta 'liq pula tidak diterima kerana perbuatan ta 'liq adalah satu bentuk perjudian atas perkara yang tidak wujud ketika akad. Selain itu, pemberian dengan cara ta 'liq menggambarkan bahawa penghibah tidak benar-benar rela untuk melepaskan hak milik hartanya melalui hibah (Abu Zahrah, 1996; Subhi Mahmasani, 1972).

Selain tiga bentuk syarat tersebut, pensyaratan dalam hibah juga boleh berlaku dalam sighah yang berbentuk taqyid (akad yang pelaksanaannya tertakluk kepada syarat). Dalam konteks hibah, taqyid berlaku apabila penghibah meletakkan sesuatu syarat sampingan bersama-sama akad hibah bagi melaksanakan pemberiannya sama ada syarat itu menepati kehendak akad hibah (muqtada alhibah) atau sebaliknya. Pemberian hibah seumpama ini bolehlah dikategorikan sebagai hibah yang disertakan dengan syarat, iaitu al-hibah al-muqtarinah bi shart atau dalam Bahasa Inggerisnya disebut sebagai gifts with conditions (Kamila Tyabji, 1949).

Hukum meletakkan syarat seumpama ini adalah bergantung kepada status syarat yang dibuat itu sendiri sama ada ianya selari dengan kehendak akad atau al-shart al-fasid iaitu yang bercanggah dengan kehendak akad. Al-shart al-fasid dalam hibah berlaku apabila penghibah menetapkan syarat yang bertentangan dengan kehendak akad hibah seperti mensyaratkan supaya mawhub tidak dijual, tidak dihibah, atau mesti dijual kepada orang tertentu dan seumpamanya. Contoh lain ialah penghibah meletakkan syarat yang dianggap mustahil seperti hibah dengan syarat terbang ke langit tanpa sebarang alat dan syarat yang tidak selari dengan etika dan undang-undang seperti suami menghibah kepada isteri yang diceraikan dengan

meletakkan syarat bahawa bekas isterinya tidak boleh berkahwin sepanjang umurnya atau seorang menghibah kepada seorang wanita dengan syarat wanita itu melakukan zina dengannya. Jika syarat itu ialah al-shart al-fasid, maka syarat tersebut dihukumkan batal manakala akad hibah tetap sah (al-Bahuti, 1982; al-Khatib, Muhammad al-Sharbini, t.t.). Akad hibah disifatkan tidak batal dalam keadaan ini kerana hibah merupakan sejenis akad sukarela ('uqud al-tabarru'at) yang tidak terbatal dengan pemasukan syarat-syarat yang rosak.

Antara keadaan hibah yang disertakan syarat yang dibahaskan dalam fiqh ialah hibah dengan syarat balasan, hibah dengan mensyaratkan penerima hibah melakukan atau tidak melakukan sesuatu tindakan, hibah dengan mensyaratkan penerima hibah tidak bertasarruf dengan mawhub, hibah dengan mensyaratkan penerima hibah menunaikan hutang penghibah, dan hibah yang disyaratkan untuk berkuatkuasa selepas kematian penghibah. Pensyaratan juga berlaku apabila penghibah menetapkan bahawa dia masih mempunyai hak manfaat ke atas harta tersebut. Keadaan-keadaan ini dianggap syarat yang pada kebiasaannya ditetapkan oleh penghibah kepada penerima hibah. 
Bagi keadaan pertama, hibah dengan syarat balasan berlaku apabila penghibah dalam akad hibahnya menyatakan bahawa dia akan menghibahkan sesuatu harta miliknya dengan syarat penerima hibah tersebut membalas pemberiannya dengan sesuatu yang telah ditetapkannya dalam akad. Hibah jenis ini merupakan akad jual beli. Oleh itu, syarat supaya penerima hibah memberikan balasan ke atas hibahnya adalah syarat yang dianggap sah dan penerima hibah perlu mematuhi syarat tersebut untuk menjadikan akad hibah berkuatkuasa. Memandangkan hibah dengan syarat balasan adalah menyerupai akad-akad pertukaran ( $m$ ' 'awadat), maka untuk mengekalkan status pemberian dengan syarat balasan ini sebagai akad tabarru', sesetengah undang-undang sivil negara Islam (misalnya, Perkara 495 (2) Undang-undang Sivil Mesir dan Perkara 463 (2) Undang-undang Sivil Syria) memperuntukkan bahawa nilai balasan yang disyaratkan perlulah lebih kecil daripada nilai mawhub. Jika balasan yang disyaratkan oleh penghibah itu melebihi nilai mawhub, maka penerima hibah hanya perlu memberikan balasan yang mempunyai nilai yang sama dengan mawhub tersebut (Perkara 498 Undang-undang Sivil Mesir dan Perkara 466, Undang-undang Sivil Syiria). Namun, menurut amalan di Lubnan, apabila balasan yang diberikan oleh penerima hibah itu sama nilainya dengan mawhub atau hampir-hampir menyamainya ataupun melebihi nilai mawhub tersebut, maka pada keadaan ini transaksi sedemikian dianggap sebagai jual beli dan bukan lagi hibah. Walau bagaimanapun, perkara ini tidak diperuntukkan secara jelas dalam Undang-undang Sivil Lubnan (Nadir 'Abd al-'Aziz Shaqi, 2002; Mu'awwad 'Abd al-Tawwab, 1987).

Selain penetapan syarat balasan yang berbentuk material dalam akad hibah, pensyaratan dalam hibah juga boleh berlaku dalam bentuk yang lain. Antara contoh syarat bukan dalam bentuk material ialah syarat penunaian hutang dan syarat melakukan sesuatu tindakan. Pensyaratan dalam hibah juga boleh berlaku apabila penghibah meletakkan terma dalam hibahnya bahawa penerima hibah perlu atau tidak perlu melakukan suatu perbuatan atau tindakan tertentu. Contoh syarat ini ialah penghibah mensyaratkan penerima hibah mengusahakan tanahnya atau mensyaratkan penerima hibah agar tidak bertasarruf dengan harta hibahnya). Walau bagaimanapun, pensyaratan tersebut perlu memenuhi peraturan umum untuk menjadikannya boleh dikuatkuasakan, iaitu (al-Sanhuri, t.t.; Nadir 'Abd al'Aziz Shaqi, 2002):

i. Perkara yang disyaratkan mestilah suatu yang tidak mustahil untuk ditunaikan

ii. Syarat tersebut mestilah ditentukan dengan jelas

iii. Syarat itu juga hendaklah tidak menyalahi etika dan undang-undang

Berkenaan syarat tidak bertasarruf dengan mawhub, ia berlaku apabila penghibah mensyaratkan agar penerima hibah tidak melakukan apa-apa transaksi terhadap harta yang dihibahnya seperti disyaratkan tidak boleh dijual, tidak boleh dihibahkan semula, dan tidak boleh diwakafkan. Secara umumnya, syarat seumpama ini dihukumkan sebagai batal kerana bertentangan dengan hakikat hibah itu sendiri. Apabila hibah dilakukan, pemilikan harta hibah itu bertukar kepada penerima hibah yang akan berhak untuk melakukan apa sahaja terhadap harta tersebut termasuk bertasarruf. Dengan demikian, syarat yang menyekat penerima hibah daripada bertasarruf adalah batal (dianggap tidak wujud) walaupun hibah itu sendiri sah dan berkuatkuasa jika memenuhi rukun dan syaratnya (al'Aqil, 1978).

Dalam undang-undang hibah di negara-negara Islam, penetapan syarat tidak boleh bertasarruf tidak dinyatakan secara jelas. Namun, pengamalan syarat tersebut dikenalpasti berdasarkan peruntukan-peruntukan umum undang-undang yang ada di negara-negara berkenaan. Pensyaratan sekatan daripada bertasarruf adalah sah dan mengikat sekiranya ia memenuhi syarat-syarat yang telah ditetapkan, iaitu syarat tersebut mestilah diasaskan kepada tujuan yang dibenarkan dan hanya terhad kepada satu tempoh yang munasabah. Penilaian terhadap sesuatu tempoh yang ditetapkan untuk sekatan tasarruf itu sama ada dianggap munasabah atau sebaliknya adalah ditentukan oleh mahkamah berdasarkan, antara lain kepada keadaan kes dan juga kemaslahatan yang ingin dicapai melalui pensyaratan tersebut. Ini bermakna tiada tempoh tertentu yang perlu dipatuhi bagi sesuatu tujuan. Oleh itu, tempoh tersebut boleh ditetapkan mengikut tempoh hidup penghibah, penerima hibah atau pihak ketiga. Berkenaan tujuan atau motif kepada pensyaratan sekatan bertasarruf, hendaklah ia tidak bercanggah dengan undang-undang dan tatasusila secara umum. Undang-undang Kuwait dan Lubnan memperincikan lagi syarat ini bahawa tujuan pensyaratan sekatan berupa satu tujuan yang kuat. Dalam konteks ini, sekatan bertasarruf mestilah bertujuan untuk merealisasikan kemaslahatan yang besar dan dibenarkan kepada pihak penghibah, penerima hibah, atau pihak ketiga. (al-Sanhuri, t.t.; Badr Jasim al-Ya'qub, 1986; Nadir 'Abd al-'Aziz Shaqi, 2002). 
Seterusnya, hibah beserta syarat juga berlaku dengan penghibah mensyaratkan agar penerima hibah menunaikan hutangnya. Apabila penerima hibah bersetuju dengan sesuatu syarat dan mengambil milikan terhadap mawhub, maka dia berkewajipan untuk menunaikan syarat tersebut. Hal ini sebagaimana diperundangkan dalam undang-undang sivil di negara-negara Islam (misalnya Perkara 499, Undang-undang Sivil Mesir). Hutang yang dimaksudkan ialah menganggap hutang itu adalah hutang yang telah ada pada waktu hibah dibuat. Nilaian hutang yang disyaratkan untuk dibayar oleh pihak penerima hibah mestilah tidak melebihi nilai harta hibah tersebut. Jika penerima hibah gagal untuk menunaikan syarat ini, maka hibah boleh dibatalkan atas permintaan penghibah.

Berkenaan pensyaratan bahawa pemilikan atau pindah milik hanya berlaku selepas kematian penghibah. Jika penghibah mensyaratkan agar hibahnya berkuatkuasa selepas kematiannya, maka hibah tersebut tidak sah, namun ia dianggap sebagai wasiat dan tertakluk kepada hukum-hakam wasiat (al-Sanhuri, t.t.).

Antara yang terpenting apabila membincangkan mengenai pewarisan harta menerusi hibah ialah, penghibah masih lagi ingin memanfaatkan harta tersebut selagi dia masih lagi bernyawa. Hal ini bagi menjamin kedudukannya pada masa hadapan walaupun harta milik mereka telah dihibahkan kepada orang lain. Ini kerana keadaan masyarakat pada zaman serba moden sekarang amat mencabar sehinggakan anak boleh mengabaikan ibu bapa. Oleh itu sebagai persediaan maka syarat tersebut adalah relevan dan diperlukan. Pemberi hibah masih menguasai harta hibah seolah-olah tiada pindah milik atau penguasaan penerima. Konsep ini dibuat kerana pemberi hibah khuatir mungkin penerima hibah akan mengabaikannya apabila semua harta telah dihibahkan. Dengan kata lain, bukan menjadi motif utama pemberi hibah enggan memberikan harta kepada penerima hibah akan tetapi sebagai mewujudkan suatu jaminan agar tidak dikhianati penerima hibah (Naziree Md Yusof, 2009).

Akhirnya, hibah beserta syarat juga berlaku dalam persoalan menetapkan tempoh sesuatu hibah berdasarkan kematian, iaitu apa yang dikenali sebagai 'umra dan ruqba. Definisi 'umra dari segi istilah syarak berbentuk teknikal tidak diutarakan oleh para fuqaha. Yang ada cuma gambaran bagaimana 'umra itu berlaku dalam bentuk lafaz sighah. Walau bagaimanapun, didapati ahli fiqh Maliki dalam penulisan mereka telah memberikan definisi 'umra secara khusus. Al-Dusuqi (2005) misalnya mentakrifkan 'umra sebagai pemberian manfaat harta sepanjang hayat penerima hibah tanpa balasan. Berdasarkan hal ini, dengan dengan syarat 'umra bagi mazhab Maliki bukanlah pemberian dalam erti kata memindah milikkan harta itu sepenuhnya sebagaimana difahami oleh fuqaha jumhur, bahkan ianya adalah satu bentuk pinjaman atau pemberian hak untuk menggunakan manfaat harta tersebut sahaja (al-'Adawi, t.t.). Secara umum, takrif 'umra yang boleh dikemukakan ialah, "Satu bentuk pemberian hak milikan terhadap sesuatu harta kepada seseorang dengan menetapkan atau menghadkan tempoh pemilikannya berdasarkan kematiannya atau kematian orang yang diberi itu." (Nasrul Hisyam, 2012).

Manakala ruqba bermaksud pemberian hak milik daripada seseorang kepada yang lain, yang mana jika salah seorang daripada penghibah dan penerima itu mati, mawhub akan menjadi hak milik orang yang masih hidup (Ahmad Rida,1960; al-Sharbasi, 1981). Gambaran sighah ruqba, adalah seperti, "(Rumah) ini untuk kamu sepanjang hayat kamu, sekiranya kamu mati sebelumku ia kembali kepadaku, (namun) jika aku mati sebelum kamu maka ia menjadi milikmu" (Ibn Qudamah, t.t.).

Umumnya, hibah yang disyaratkan 'umra dan ruqba adalah sah di sisi majoriti fuqaha (Ibn Qudamah, t.t.). Cuma perselisihan pendapat di kalangan mereka adalah sama ada kedua-dua syarat itu mengikat (binding) atau sebaliknya. Syarat-syarat 'umra dan ruqba tidak boleh dikuatkuasakan di sisi jumhur fuqaha kerana ia bertentangan dengan prinsip dan kehendak kontrak hibah tersebut. Hal ini juga berasaskan bahawa subjek kepada kontrak 'umra dan ruqba itu adalah fizikal, bukannya manfaat harta. Namun, bagi mazhab Maliki mereka berpendapat bahawa subjek kepada kontrak tersebut adalah manfaat dan oleh kerana itu syarat supaya mengembalikan mawhub adalah mengikat (Nasrul Hisyam, 2012). 


\subsection{APLIKASI DAN POTENSI HIBAH BERSYARAT SEBAGAI INSTRUMENN PERANCANGAN HARTA}

Perancangan adalah asas kepada keberkesanan sesuatu matlamat perwarisan harta.Proses perancangan harta bukan hanya sekadar mengumpul, mengurus dan melindungi harta semata-mata, sebaliknya harta dan kekayaan yang dimiliki harus dipastikan dapat diwarisi dengan baik tanpa menimbulkan kesulitan kepada waris yang layak menerimanya. Objektif utama perancangan harta ialah untuk menunaikan tanggungjawab pada diri sendiri serta waris yang ditinggalkan. Keduanya, ialah untuk memastikan harta pusaka ditadbirkan mengikut garis panduan yang betul sama ada dibahagikan mengikut kaedah faraid, hibah, wasiat dan sebagainya. Ini bertujuan supaya harta tersebut dapat diuruskan dengan secepat yang mungkin selepas kematian serta setiap ahli waris mendapat hak masing-masing, seterusnya dapat mengelakkan persengketaan. Akhir sekali, perancangan harta dalam Islam dilihat sebagai suatu usaha melakukan amal kebajikan yang kekal ganjaran pahalanya sehingga hari kiamat. Sebagai contoh merancang harta yang dimiliki untuk pemberian secara wasiat, wakaf, sedekah, hibah dan sebagainya (Abdul Aziz Hassan, 2007).

Secara ringkasnya perancangan harta adalah suatu perancangan yang mampu dilaksanakan cara mana seseorang semasa hayatnya memperoleh, mengurus dan mengagihkan hartanya kepada wariswaris dan benifisiari mengikut budi bicara serta adil disamping ia dapat mengawal, memantau dan memanfaatkan harta itu untuk penerima, dirinya dan keluarga semasa hayat dan selepas kematian (Othman Yaacob, 2006). Ini membolehkan seseorang itu menentukan perjalanan hartanya dan kepada siapakah hartanya patut diberikan dan ia sah dari segi undang-undang sama ada sivil mahupun syariah.

Pelbagai kaedah yang boleh digunakan bagi pelupusan dan perancangan harta dalam kalangan masyarakat Islam seperti faraid, wasiat serta hibah. Namun kesesuaian kaedah tersebut adalah berbeza ia bergantung kepada keadaan dan masalah yang dihadapi. Menurut Rusnadewi Abdul Rashid dan Nor Hisyam Ahmad (2013), pelaksanaan hibah dilihat amat sesuai untuk diamalkan seiring dengan peredaran masa serta perubahan corak hidup dan tabiat masyarakat. Ini adalah memandangkan pengagihan harta secara hibah tidak perlu melalui proses pentadbiran seperti yang diperlukan dalam permohonan dan penyelesaian harta pusaka secara faraid. Justeru itu, tidak timbul masalah dari segi kelewatan dan tunggakan kes pengagihan harta. Selain daripada itu, masalah pengabaian pembahagian harta juga tidak akan timbul memandangkan pemberian telah dibuat semasa hayat si mati kepada waris-waris tersebut. Keharusan amalan hibah disokong dengan pelbagai asas yang kukuh sama ada daripada nas al-quran, hadis, mahupun pandangan para sahabat bahkan dianggap thabit menerusi ijmak. Antara kebaikan produk hibah ialah (Ameer Azeezy, 2009):

i. Harta yang dihibahkan akan terkeluar dari harta pusaka. Apabila seseorang meninggal maka setiap harta yang ditinggalkan akan diklasifikasikan sebagai harta pusaka. Sebelum harta itu dibahagikan, mahkamah akan meneliti sama ada si mati ada membuat Dokumen Hibah atau tidak. Jika si mati ada membuat Dokumen Hibah, maka harta yang dihibahkan akan terkeluar dari hukum harta pusaka.

ii. Harta yang telah dihibah tidak boleh dituntut oleh waris yang lain. Hibah adalah satu akad yang sangat kuat untuk seseorang memberi atau melupuskan harta kepada orang lain. Harta yang telah dihibahkan secara automatiknya menjadi harta penerima hibah. Waris penghibah (pemberi hibah) tidak berhak untuk menuntut harta yang telah dihibah, kerana harta itu telah menjadi milik penerima hibah.

iii. Pewarisan harta dapat dibuat dengan pantas. Dengan adanya dokumen pengisytiharan hibah, maka pemindahan harta dapat dibuat dengan pantas, kerana harta yang telah dihibahkan tidak perlu melalui proses pembahgian harta pusaka, kerana harta yang telah dihibahkan tidak lagi di bawah pemilikan penghibah. Apabila penghibah meninggal dunia maka harta tersebut telah keluar dari harta pusaka.

iv. Formula pembahagian yang bebas, ini berbeza dengan hukum faraid dalam bab harta pusaka, kedudukan harta hibah adalah terserah kepada pemberi hibah untuk menentukan berapa bahagian yang akan diterima dan penerimanya.

Apabila pemilik harta menghibahkan hartanya, maka dari sudut undang-undang harta tersebut tidak lagi tertakluk kepada undang-undang pembahagian pusaka dan pewarisan sepertimana yang 
terkandung didalam Akta Pentadbiran dan Probet 1959, Akta Wasiat mahupun sistem wasiat dan faraid. Ini menyebabkan pemindahan milikan harta menjadi mudah dan cepat.

Sememangnya diakui bahawa sama ada hibah bersyarat ini boleh diaplikasi atau sebaliknya adalah menjadi perkara khilaf dalam kalangan sarjana. Namun demikian, penulis berpandangan prinsip hibah bersyarat ini perlu dilihat secara dari perspektif yang lebih luas termasuklah kepada prinsip-prinsip umum syariah dan juga pemahaman kepada realiti semasa berkenaan keperluannya. Hibah bersyarat dilihat berpotensi untuk menjadi instrumen perancangan harta yang baik dan mempunyai kelebihannya tersendiri berbanding instrumen perancangan harta yang lain. Selain faraid dan wasiat, hibah, termasuk hibah bersyarat juga merupakan salah satu cara pelupusan harta yang dianjurkan oleh syarak. Dakwaan yang mengatakan bahawa hibah bertujuan untuk membelakangi sistem pembahagian harta secara faraid adalah perlu diperbetulkan.

Terdapat beberapa keadaan yang memerlukan kepada hibah bersyarat supaya mereka yang tergolong dalam keadaan ini tidak terabai atau teraniayai disebabkan perebutan harta yang berlaku atau disebabkan hak pewarisan terhalang oleh ahli waris yang lain. Antara yang boleh memanfaatkan instrumen hibah bersyarat ini ialah orang yang mempunyai pewaris anak perempuan sahaja. Mengikut pembahagian harta dalam Islam, jika seseorang hanya mempunyai waris perempuan sahaja maka waris perempuan akan mendapat $1 / 2$ sahaja daripada harta tersebut dan selebihnya akan di bahagikan kepada ahli waris yang berhak mengikut faraid. Jika pemilik harta tidak ada ahli waris yang lain maka harta tersebut akan diberikan ke Baitulmal (al-Sabuni, 2008). Dalam situasi ini, pemilik harta boleh membuat hibah agar sejumlah tertentu hartanya diberikan kepada anak perempuannya, sebagai pelengkap kepada bahagian faraid yang bakal diperolehi selepas kematiannya.Dengan hibah tersebut, bermaksud pemilik harta melepaskan haknya terhadap harta yang dihibahkan dan penghibah tidak lagi mempunyai apa-apa hak termasuk manfaat harta dari segi undang-undang (sungguhpun dari segi syarak, ibu dan bapa boleh menarik kembali hibah yang diberikankan kepada anaknya). Namun, jika pemilik harta menggunakan hibah bersyarat sebagai instrumen pewarisan dalam kes ini, kedudukan di sisi undang-undang tidak sepertimana yang disebutkan. Penghibah boleh, misalnya, meletakkan syarat bahawa dia masih berhak menikmati hasil atau menggunakan harta hibah itu selagi mana dia masih hidup. Begitu juga, dia boleh membuat syarat ruqba bagi menangani keadaan kamatian anak tersebut lebih dahulu daripadanya.

Individu yang mempunyai anak angkat juga dicadangkan untuk mengaplikasikan hibah bersyarat. Anak angkat ialah anak yang diambil dan dijadikan sebagai anak sendiri (Kamus Dewan, 2007). Pemberian hibah adalah salah satu cara yang dapat dilakukan oleh keluarga angkat kepada anak angkatnya sebagai tanda wujud kasih sayang yang telah terjalin antara keduanya. Ini kerana Islam secara jelas menegaskan bahawa hubungan antara keluarga angkat dengan anak angkatnya tidak menyebabkan keduanya mempunyai hubungan waris mewaris, dengan demikian seorang anak angkat tidak mewarisi harta keluarga angkatnya. Islam tidak melarang mengambil anak angkat, namun hukumnya tidak seperti anak sendiri, malah tetap anak orang lain. Allah S.W.T. berfirman yang bermaksud, "Dan ia juga tidak menjadikan anak-anak angkat kamu, sebagai anak kamu sendiri".(Surah Al-Ahzab, 33:4). Dengan turunnya ayat tersebut, Islam melarang menasabkan anak angkat kepada bapa angkat. Disamping itu, anak angkat tidak berhak mewarisi harta bapa angkat atau keluarga angkat dan begitu juga sebaliknya, bapa angkat juga tidak berhak mewarisi peninggalan anak angkatnya. Anak angkat tidak termasuk sebagai ahli waris yang berhak dalam faraid, oleh itu sebagai anak angkat mereka tidak ada hak untuk mempertikai dan menuntut apa-apa harta yang ditinggalkan oleh keluarga angkat mereka.

Syariat Islam memberi ruang bagi seseorang untuk memperoleh amal kebaikan dengan memberikan sebagian dari harta peninggalannya dalam bentuk hibah kepada anak angkat untuk memenuhi keperluan hidupnya dimasa akan datang. Ini bagi mengelakkan daripada mereka terabai dari segi pendidikan dan kehidupan disebabkan kesempitan hidup yang dihadapi. Namun, pemberian hibah, terutamanya kepada bukan kalangan anak kandung memberikan implikasi bahawa harta hibah tidak boleh ditarik balik selepas sempurnanya pemberian tersebut. Ini termasuklah hibah kepada anak angkat seperti yang diputuskan dalam kes Eshah bt. Abdul Rahman v Azuhar b. Ismail [1997] $2 \mathrm{JH}$ 219. Untuk menangani isu ini, maka hibah dalam bentuk 'umra atau ruqba boleh digunakan.

Ada dalam kalangan pemilik harta mempunyai ahli waris yang kurang kemampuan yang perlu diberi pertimbangan khusus. Dalam istilah ilmu faraid, ahli waris yang atau kerabat yang tidak 
termasuk dalam golongan yang menerima pewarisan dipanggil zawil arham contohnya seperti cucu dari anak perempuan sama ada cucu itu lelaki atau perempuan. Kebanyakan zawil arham adalah kerabat dari sebelah ibu. Imam Malik dan Imam Syafii berpendapat bahawa zawil arham tidak berhak menerima warisan. Sekiranya si mati tidak mempunyai ahli waris dari ashabul furudh atau asabah, tetapi hanya ada zawil arham maka harta peninggalannya akan diserahkan kepada Baitul Mal bukan kepada zawil arham (al-Sabuni, 2008). Apabila berlaku hal yang sedemikian ini merupakan satu kerugian yang sangat besar kepada ahli waris, terutamanya bagi ahli waris yang kurang kemampuan ataupun berpenyakit dan orang kelainan upaya (OKU) yang menyebabkan mereka memerlukan rawatan, tidak mampu bekerja dan menjalani kehidupan seperti insan lain. Maka, dalam hal ini hibah berperanan dalam membantu ahli waris yang kurang kemampuan tersebut bagi menampung keperluan hidup mereka. Sebagai tambahan, penghibah, dalam konteks ini ibu atau bapa boleh melantik pemagang amanah bagi menguruskan harta pusaka untuk kebajikan anak tersebut.Hal ini juga termasuk dalam konsep hibah bersyarat kerana pihak-pihak terlibat perlu mematuhi syarat-syarat yang dipersetujui bersama.

Seterusnya, dalam kes poligami.Islam mensyaratkan kepada sesiapa yang ingin berkahwin lebih daripada satu supaya memberi keadilan kepada setiap isterinya mengikut keadaan keperluan isteri tersebut. Jika tidak mampu berlaku adil, maka dilarang untuk berkahwin lebih daripada satu. Bagi orang yang berpoligami mestilah membuat perancangan harta yang lebih teliti dan rapi agar pembahagian harta dalam kalangan isteri dan anak-anak dalam dilakukan sebaiknya. Dalam pengiraan faraid, pembahagian harta bagi lelaki yang meninggalkan dua isteri, dua anak lelaki, dan dua anak perempuan sebagai contoh ialah seperti di bawah:

\begin{tabular}{||l||c|c|}
\hline \multicolumn{1}{|c|}{ Waris } & Pembahagian & Tashih \\
\hline \hline 2 Isteri & $1 / 8$ & $6 / 48$ \\
\hline \hline 2 Anak Perempuan & $7 / 24$ & $14 / 48$ \\
\hline \hline 2 Anak Lelaki & $7 / 12$ & $28 / 48$ \\
\hline
\end{tabular}

Berdasarkan pembahagian di atas, hibah boleh diberi kepada isteri bagi mengimbangi hak pusakanya.Ini sudah tertentu tertakluk kepada pertimbangan keadaan dan situasi yang berbeza antara isteri.Berdasarkan hal ini, syarat-syarat tertentu boleh diletakkan dalam hibah berkenaan.

Hal keadaan yang sama juga boleh berlaku dalam kes muallaf. Mualaf ialah saudara baru yang memeluk Islam, bagi orang yang memeluk agama Islam dan mati meninggalkan harta, jika tidak ada waris lain yang beragama Islam maka harta tersebut akan jatuh ke tangan baitulmal. Mualaf boleh merancang harta dengan menghibahkan harta mereka kepada ahli waris yang bukan beragama Islam. Hibah dilihat dapat menangani masalah ahli keluarga yang bukan Islam seperti anak yang telah memeluk Islam sedangkan ibu dan bapa masih dalam agama lama. Sama juga keadaannya bagi suami isteri mualaf yang tidak mempunyai waris. Penggunaan syarat ruqba dalam hibah antara mereka terutama yang melibatkan rumah yang sedang didiami (yang juga satu-satunya harta yang dimiliki) boleh mengelakkan daripada harta tersebut berpindah milik kepada baitulmal dan seterusnya akan menyulitkan pasangan yang masih hidup untuk mendapatkan semula harta tersebut (Nasrul Hisyam, 2012).

Hibah bersyarat, khususnya ruqba dikatakan boleh menyelesaikan masalah pemilikan dan pewarisan hartanah di negara-negara minoriti muslim atau kedudukan orang Islam di satu-satu kawasan itu adalah lemah. Penggunaan hibah ruqba dalam situasi seperti ini dapat menjamin pemilikan harta tersebut dapat dikekalkan kepada penghibah atau penerima hibah apabila salah seorang daripadanya mati. Jika tidak, dibimbangi pemilikan hartanah di kalangan orang-orang Islam semakin berkurangan (akibat penjualan, pecahan dan sebagainya) dan ini akan menyebabkan survival mereka di negara berkenaan tidak dapat dipertahankan.

\subsection{PENUTUP}

Berdasarkan perbincangan di atas, penulis merumuskan bahawa hibah bersyarat adalah sesuai dijadikan instrumen perancangan harta dan dijadikan salah satu alternatif dan seiring dengan kaedah pewarisan harta yang lain. Berkenaan dengan kedudukan hibah bersyarat yang telah dibincangkan, 
sistem perwarisan atau agihan harta dalam Islam perlu dilihat secara sebagai satu entiti yang menyeluruh dan saling lengkap melengkapi. Dengan kata lain, dalam konteks perbincangan ini pemakaian hibah bersyarat adalah sebagai instrumen yang bergandingan dengan instrumen agihan harta yang lain iaitu fara'id, wasiat, amanah, wakaf, nazar, bahkan hibah itu sendiri. Dengan demikian, agihan harta yang disarankan adalah berasaskan kepada keperluan atau perancangan pemilik harta itu sendiri.

Hibah bersyarat adalah bertepatan dengan maqasid syari'ah (tujuan perlaksanaan syariah Islam) yang berkaitan penjagaan harta. Komponen maqasid ini membuktikan bahawa Islam adalah sistem hidup yang lengkap, komprehensif, relevan pada bila-bila masa dan sudah tentu boleh dilaksanakan dalam apa jua urusan kehidupan. Kesejahteraan hidup akan lebih sempurna apabila pengurusan harta dapat dilaksanakan mengikut prinsip-prinsip yang ditetapkan oleh agama Islam berteraskan Maqasid Syariah dengan menerapkan ia sebagai model strategik dalam pengurusan pentadbiran harta bagi memantapkan sistem pengurusan harta seterusnya meningkatkan ekonomi negara. Di samping pemantapan pengurusan perancangan harta ini juga sebagai teras terpenting dalam pemerkasaan institusi perlembagaan serta perundangan negara berlandaskan prinsip maqasid syariah yang berpaksikan ketelusan, kebertanggungjawaban dan urus tadbir yang baik.

Suatu bentuk kawalan bersifat undang-undang berkaitan hibah umumnya dan hibah dengan syarat khususnya perlu diwujudkan di Malaysia sebagaimana yang telah wujud di negara-negara Islam yang lain. Persoalan kesahihan hibah bersyarat sewajarnya diberikan penelitian yang mendalam dan perlu dibincangkan diperingkat yang lebih tinggi seperti Jawatankuasa Fatwa Kebangsaan. Di samping melakukan penambahbaikan mengikut keperluan dan maslahat masyarakat di negara ini. Melihat kepada kesedaran yang tinggi masyarakat Islam di negara ini tentang pentingnya merancang harta sebelum berlaku kematian serta pertumbuhan pesat industri perancangan harta, adalah menjadi suatu keperluan yang mendesak kepada kewujudan dan penggubalan suatu bentuk kawalan dan selian undang-undang khusus berkenaan hibah bagi mengelakkan pelbagai isu berbangkit timbul.

\section{RUJUKAN}

'Ali al-Khafif (1996). Ahkam al-Mu'amalat al-Shar 'iyyah. Kaherah: Dar al-Fikr al-'Arabi.

'Ali Haydar (t.t.). Durar al-Hukkam Sharh Majallat al-Ahkam, j. 2. Beirut: Dar al-Kutub al-'Ilmiyyah.

Abdul Aziz Hassan (2007). "Perancangan Pusaka Islam” dalam Konvensyen Pewarisan Harta Islam 2007. Kuala Lumpur: Amanah Raya Berhad.

Abu Zahrah (1996). al-Milkiyyah wa Nazariyyat al- 'Aqd fi al-Shari 'ah al-Islamiyyah. Kaherah: Dar al-Fikr al'Arabi.

Ahmad Rida, al-Sheikh (1960). Mu 'jam Matan al-Lughah, j. 5. Beirut: Dar Maktabat al-Hayah

al-'Aqil, 1978. 'Aqd al-Hibah Bayn al-Fiqh al-Islami wa al-Qanun al-Madani. Kaherah: Dar al-Huda.

al-'Asqalani, Ahmad bin 'Ali bin Muhammad bin Hajar (t.t.). Fath al-Bari bi Sharh Sahih al-Bukhari, j. 5.

Kaherah: Dar al-Taqwa.

al-Adawi, 'Ali al-Sa'idi (t.t.). Hashiyat al-'Adawi 'ala Sharh Abi al-Hasan, j. 2. Beirut: Dar al-Fikr

al-Dusuqi, Muhammad 'Arafah (2005). Hashiyah al-Dusuqi 'ala al-Sharh al-Kabir, j. 5. Beirut: Dar al-Kutub al-'Ilmiyyah.

al-Jaziri, 'Abd al-Rahman (t.t.). Kitab al-Fiqh 'ala al-Madhahib al-Arba'ah, j. 3. Beirut: Dar al-Kutub al'Ilmiyyah.

al-Nawawi, Abi Zakariyya Mahy al-Din (t.t.). al-Majmu 'Sharh al-Muhadhdhab, j. 15. Beirut: Dar al-Fikr.

al-Sabuni, Muhammad 'Ali (2008). Al-Mawarith Fi al-Shari'ah al-Islamiyah Fi Dau'i al-Kitab Wa al-Sunnah.

Bairut, Lubnan : Syurkah Abna' Sharif al-Ansari.

al-Sanhuri, 'Abd al-Razzaq (t.t.). al-Wasit fi Sharh al-Qanun al-Madani, j. 2 dan 6. Beirut: Dar Ihya' al-Turath al-'Arabi. 
Nasrul Hisyam et al. / UMRAN - International Journal of Islamic and Civilizational Studies. Vol.3, No. 3-1 (2017) 32-41

al-Sharbini, Muhammad al-Khatib (t.t.). Mughni al-Muhtaj, j. 4. Beirut: Dar Ihya' al-Turath al-'Arabi

Ameer Azeezy Tuan Abdullah (2009). "Kedudukan Produk Hibah dalam Pasaran di Malaysia.” Jurnal ILIM, vol. 2, 87-98.

Badr Jasim al-Ya'qub (1986). 'Aqd al-Hibah fi al-Qanun al-Madani al-Kuwayti: Dirasah Muqaranah. Kuwait: Maktabah Tijariyyah Kuwayt.

Ibn ‘Abidin, Muhammad Amin (1966). Hashiyah Radd al-Mukhtar, j. 5. Mustafa al-Babi al-Halabi.

Ibn Qudamah, Muwaffaq al-Din (t.t.). al-Mughni, j. 6. Beirut: Dar al-Fikr

Kamila Tyabji (1949). Limited Interest in Muhammadan Law. London: Steens \& Sons Ltd.

Kamus Dewan (2007). Dewan Bahasa dan Pustaka

Mu'awwad 'Abd al-Tawwab (1987). Mudawwanat al-Qanun al-Madani, j. 1. Kaherah: Jalal Huzzi wa Shuraka'uh.

Muhammad Qadri Basha (1338H). Kitab Murshid al-Hayran ila Ma 'rifat Ahwal al-Insan. Kaherah: al-Maktabat al-Misriyyah.

Nadir 'Abd al-'Aziz Shaqi (2002). 'Aqd al-Hibah fi al-Qanun al-Lubnani wa al-Maqarin, j. 1. Tarablus: alMu'assasah al-Hadithah li al-Kitab.

Nasrul Hisyam (2011). Hibah dalam Undang-undang Islam: Prinsip dan Amalan. Johor Baharu: UTM Press

Nasrul Hisyam Nor Muhamad (2012). “'Umra dan Ruqba : Analisis Mengenai Kesannya Terhadap Kontrak Hibah dan Potensinya Sebagai Instrumen Agihan Harta," Shariah Journal, Vol. 20(1), 1-46

Naziree Md Yusof (2009). Mekanisme Dokumen Wasiat Amanah Raya Berhad (ARB) dan Aplikasi Hibah Ruqba: Satu Analisis. Kanun. Kuala Lumpur: Dewan Bahasa dan Pustaka

Noor Lizza Mohamed Said, Mohd Ridzuan Awang, Amir Husin Mohd Nor (2012). "Hibah Dengan Syarat Balasan Menurut Pandangan Fuqaha dan Kedudukannya dalam Undang-undang Sivil Jordan.” Jurnal Syariah, 20(3), 309-328.

Norazila Mat Hussin, Mohd Zulkhairi Esa, dan Nasrul Hisyam Nor Muhamad (2012). Kepentingan Modul Perancangan Harta di Institusi Pengajian Tinggi (IPT): Satu Pemerhatian. Prosiding Seminar Antarabangsa Perguruan dan Pendidikan Islam, 8-9 Mac 2012, Senai, Johor

Othman Yaacob (2006). "Pembentukan Trust Hibah Sebagai Alternatif Perancangan Harta". Dlm Siti Mashitoh Mahamood (ed). Harta Amanah Orang Islam di Malaysia: Perspektif Undang-undang dan Pentadbiran. Kuala Lumpur: Universiti Malaya.

Rusnadewi Abdul Rashid \& Nor Hisyam Ahmad (2013). "Pengurusan Harta Melalui Hibah: Kepentingan dan Manfaat Dari Pelbagai Aspek Untuk Kemajuan Ummah.” Jurnal Hadhari, 5(1), 91-104.

Subhi Mahmasani (1972). al-Nazariyyah al- 'Ammah li al-Mujibat wa al- 'Uqud fi al-Shari'ah al-Islamiyyah, $\mathrm{j}$. 2. Beirut: Dar al-'Ilm li al-Malayin.

Undang-undang Sivil Jordan (No. 43/1976)

Undang-undang Sivil Mesir(No. 31/1948)

Undang-undang Sivil Syria(No. 84/1949)

Undang-undang Sivil Tunisia (No. 17/1964)

Undang-undang Sivil UAE (No. 5/1985) 